\title{
Investigation of polymer and surfactant-polymer injections in South Slattery Minnelusa Reservoir, Wyoming
}

\author{
Panqing Gao $\cdot$ Brian Towler
}

Received: 29 April 2010/Accepted: 20 December 2010/Published online: 29 January 2011

(C) The Author(s) 2011. This article is published with open access at Springerlink.com

\begin{abstract}
This paper presents an investigation of the enhanced oil recovery (EOR) potential in the South Slattery Minnelusa formation. The South Slattery Field, which is characterized by low permeability and high saline brine, is stepping into the economic limits of secondary waterflood. A chemical flooding simulation model which was based on experimental parameters was set up for the potential investigation of EOR. Both polymer and surfactant-polymer floods were investigated. The recoveries of these EOR methods are presented, and the development efficiencies are analyzed.
\end{abstract}

Keywords Polymer flood · Surfactant-polymer flood . Low permeability $\cdot$ High salinity

\section{List of symbols}

$\overline{H_{w j}} \quad$ Average thickness of injection well

$H_{w j} \quad$ Thickness of injection well

$\alpha \quad$ Heterogeneous factor

$H_{o i} \quad$ Thickness of response producer

$i \quad$ Response producer

$j \quad$ Injection well

$Q_{w j} \quad$ Injection rate of polymer solution

$Q_{w} \quad$ Total injection rate of region

$V \quad$ Injection volume in 1 year

HPAM Partially hydrolyzed polyacrylamide

P. Gao $(\bowtie) \cdot$ B. Towler

Department of Chemical and Petroleum Engineering,

University of Wyoming, Laramie, WY, USA

e-mail:pgao@uwyo.edu

P. Gao $\cdot$ B. Towler

Enhanced Oil Recovery Institute,

University of Wyoming, Laramie, WY, USA

\begin{abstract}
PV Pore volume
IPV Inaccessible pore volume

IFT Interfacial tension
\end{abstract}

\section{Introduction}

The South Slattery Field is on the southwest toe of a large anticlinal structure, which is on the eastern flank of the Powder River basin. Its priority pay zone is the Minnelusa $\mathrm{A}$, which is a sequence of carbonates and sandstones formed in the Permian age. These rocks were deposited in a shallow evaporitic basin, and responses to sea-level changes were recorded. The stacking pattern, or parasequences consist of (1) a marine flood of a dune field and carbonate deposition, (2) shallowing marine deposition due to eustatic lowering of the sea level, and (3) renewed progradation of eolian dune fields (Sheppy 1986). Just as the unconformity at the top of the Minnelusa has long been recognized as an important trapping mechanism, these parasequence boundaries can also provide significant traps because the geomorphic relief on the dune fields was largely preserved during each transgression. The dominant trapping mechanism is stratigraphic. According to Sheppy, there are minor Cretaceous muddy sandstones and productive sandstones in the upper part of the sequence. But the Permo-Pennsylvanian Minnelusa "A" Formation is the principal reservoir (Towler 1991). Figure 1 shows the structure on the top of the Minnelusa formation. Table 1 presents the reservoir properties of the Minnelusa.

From 1964 to 1995, the field was in the depletion stage; the primary drive mode had been shown to be a solution gas drive, in conjunction with fluid expansion, aquifer influx, and gravity drainage (Towler 1991). At the end of 




Fig. 1 The structure map of Minnelusa formation

Table 1 Property of the South Slattery Field

\begin{tabular}{lc}
\hline Property & Value \\
\hline Porosity (\%) & 15.20 \\
Permeability (mD) & 23.34 \\
Depth (ft) & 3,785 \\
Density ( $\left.{ }^{\circ} \mathrm{API}\right)$ & 32 \\
Initial GOR (SCF/STB) & 80 \\
Initial reservoir pressure (Psi) & 3,244 \\
Bubble point pressure (Psi) & 491 \\
\hline
\end{tabular}

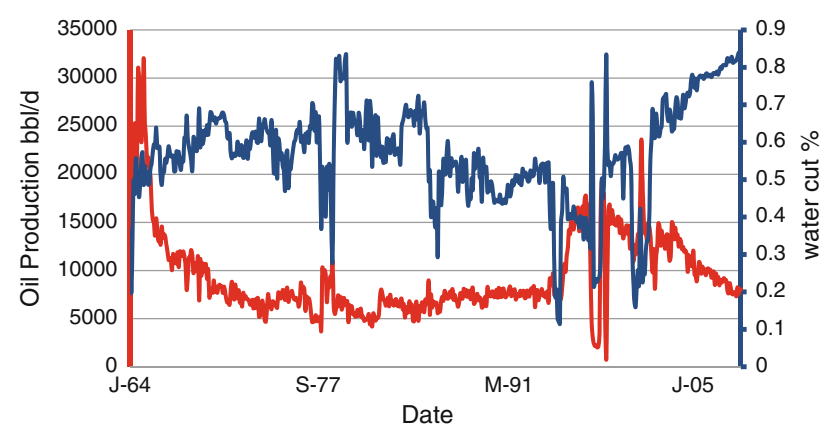

Fig. 2 Regional oil production and water cut history

this stage, the average individual water cut in the northeastern zone was relatively low, while the southwest part showed a high water cut. At the end of 1995, a holistic water flood began, and oil recovery rate was significantly increased. The interest in this simulation was initially spurred by the fact that the water cut kept increasing and the oil production rate kept decreasing in the past several years. Figure 2 shows that the oil production rate in this field began to decline since 2003. The water cut rose significantly due to the water injection. To slow down the oil production decline, an investigation of enhanced oil recovery (EOR) becomes necessary. In this EOR simulation model, two methods, polymer and surfactant-polymer (SP) floods, were investigated.
Eclipse has been employed to conduct the simulation investigation. E100 has been used to finish the history matching of the depletion and water flooding. Polymer and surfactant models were used to model the chemical injections. The parameters of chemical simulation were all from relative laboratory investigation.

\section{Screening criteria and feasibility investigation}

\section{Polymer flood}

Use of the polymeric waterflood is a technique to enhance oil recovery from a reservoir by improving the reservoir sweep and reducing the amount of injection fluid needed to produce the same amount of oil (Sorbie and Phil 1991). Polymer floods work by adding a certain amount of watersoluble polymers to the injection fluid to increase the viscosity of the injectant (Chang et al. 2006). In this way, the mobility ratio between the displaced phase and displacing phase can be reduced significantly, and the sweep volume is increased accordingly.

Two ways were investigated to optimize the mobility control: increasing the concentration and increasing the molecular weight. The former method is a question of economics; the later one, however, is a question of technical feasibility (Wang and Li 2006; Carcoana 1991). The change of molecular weights would result in the basic changes in the polymer solution properties and the solution-rock properties, such as residual reduction factor, adsorption, shear thinning, and inaccessible pore volume (Pu and Yin 2008; Kaminsky and Szafranski 2007). These parameters will impact the formation injectivity and determine the feasibility of the process. Therefore, the first task of the polymer flood for a given reservoir is to fix an injection system both technically and economically; especially for reservoirs with strong heterogeneity (Gharbi 2001; David and Gary 2003), the optimization of the polymer injection system is extremely important. In this research, three kinds of polymer of different molecular weights were used to estimate the effects of polymer flood in this field.

According to industry experience, the criteria for developing a successful polymer flood include the following:

1. The oil gravity is greater than $25^{\circ}$ API with an oil viscosity less than $30 \mathrm{cp}$ at reservoir conditions.

2. Oil saturation greater than $30 \%$ and light intermediates desirable.

3. The oil reservoir depth must be less than $8,000 \mathrm{ft}$ with a reservoir temperature less than $175^{\circ} \mathrm{F}$.

4. Formation permeability should be greater than $20 \mathrm{mD}$ with a net thickness (sandstones preferred) of greater than $10 \mathrm{ft}$ is favorable. 
5. Salinity environment which depends on the selected polymer.

\section{Surfactant-polymer flood}

The success of an SP flood depends upon the ability to propagate the surfactant and polymer, overcome chemical adsorption, and improve the sweep efficiency and displacement efficiency (Osterrloh and Jante 1992; Gabitto 2006). The mechanism mainly combines the function of the surfactant in decreasing interfacial tension and the function of the polymer in mobility control. The former function is used to improve the displacement efficiency; the later function is used to increase the sweep efficiency.

There are several factors that influence the actual SP process, which includes the mobility control design, surfactant concentration, residual permeability reduction, surfactant retention, dispersion of the surfactant slug, and the rheological behavior of surfactant solution in a porous medium (Gabitto 2006). With regard to the design of the flood process, all factors should be taken into account, and correlations should also be considered. For a fieldscale SP flood, the screening criteria are similar to that of a polymer flood. What must be mentioned is that net pay is not a critical consideration for an SP flood and the favorable viscosity can increase to $35 \mathrm{cp}$ at reservoir conditions.

\section{Fundamental modeling}

The research mainly covered the history match, analysis of the current injection and production system, and the estimation of different EOR methods. The simulation model was based on the properties of the South Slattery Field. A $110 \times 114$ grid model consisting of three layers was defined to describe the reservoir. Totally, 25 wells were involved in the simulation. The active cell number was 13,266 .

\section{History match}

The important history matching indices included water cut, production, reservoir pressure, bottomhole pressure, and production GOR. The accuracy of history matching is important to the following simulation work. In the history match, the RMS errors are less than $6.5 \%$ averagely. Instead of explaining the history matching in detail here, the author made analysis of history matching to have more space to illustrate the EOR simulation.

The depletion stage was from 1964 to 1985 . Seven production wells were drilled during this stage. The main mechanism has been shown to be solution gas drive, in conjunction with fluid expansion and gravity drainage. By analyzing the geological data and the development history, the bottom water breakthrough also played an important role, especially in slowing the pressure drop. The invading aquifer, which intruded into the southwest nose of the reservoir, resulted in an imbalance of the reservoir pressure, thus an imbalance of the production and water cut. At the end of this stage, the average individual water cut in the northeastern zone was less than $5 \%$, while the southwestern part was roughly $65 \%$.

The water flood began in 1995. Three injectors started injecting in this year. The oil production rate was increased by $60 \%$. During the water flood, the imbalance of pressure and a low sweep volume factor also existed. The recovery factor was $36.13 \%$ at the end of the history match of the primary and secondary phases. According to the outcomes of simulations, only some of the producers responded to the injected water. Others were still dominated by the solution gas drive. Some un-swept areas were left, especially the north part of the reservoir, which has not been swept well by the water flood. There were two factors which formed the rich zone of the remaining oil in the central reservoir: (1) the unevenness of production and injection and (2) the heterogeneous nature of the reservoir. There is also a blind side on the boundary of the reservoir where it is difficult to form a circulation of the reservoir fluids in a closed region.

\section{Development adjustment}

A robust network pattern is fundamental to a successful water flood. As analyzed above, the existing well pattern was imperfect. To improve the sweep efficiency and to raise the recovery, a pattern adjustment was necessary. Based on the outcomes of the history match, three new injectors were assigned to the rich remaining oil zone (designated New-1, 2, and 3). Meanwhile, to minimize the imbalance of the reservoir pressure, three producers were converted to injectors. The new pattern has five injectors and nine producers (some producers were shut in during the water flood), as seen in Fig. $3 b$.

Result The adjustment has improved the flood efficiency significantly by comparing the oil saturation maps with different well patterns. Through the saturation change, we can see that the un-swept areas were mobilized gradually after the network adjustment. The number of responding producers increased. As shown in Fig. 4, the incremental recovery of the new well pattern is much higher than that of the old one. When the water cut reaches $97 \%$ in 2038, the adjusted pattern has an incremental recovery of $3.85 \%$. 



Fig. 3 a Existing network, b network after adjustment

\section{EOR investigation}

The significant improvement in oil recovery makes EOR technologies more and more widely accepted in the petroleum industry. In this research, the simulation method was used to estimate the feasibility of some EOR methods at the South Slattery Field. As we know, the adoption of an EOR method mainly depends on the characteristics of the reservoir and the efficiency of the current development. Theoretically, the Slattery Field has the conditions for the success of the EOR methods mentioned above. The

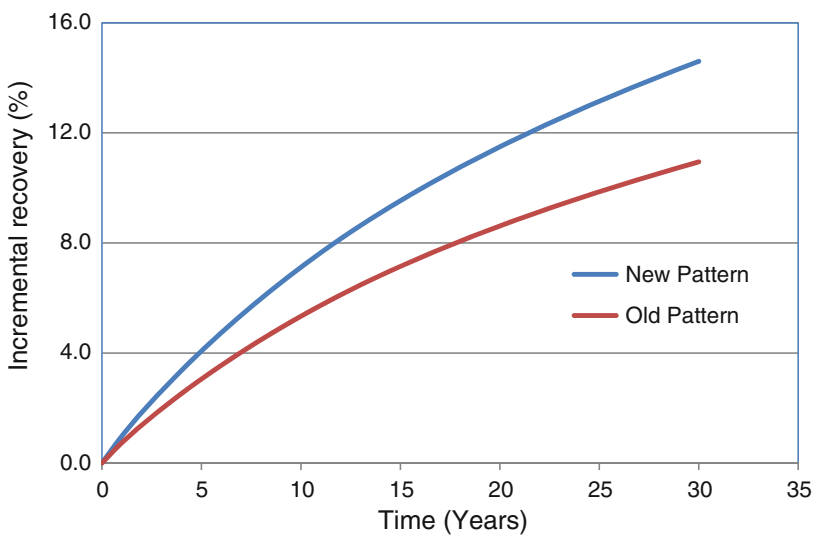

Fig. 4 Incremental recoveries for different networks

research evaluated the development efficiencies of the EOR methods. Several plans were designed to optimize the key indices for different EOR methods. According to the economic injection volume of chemical in Daqing, China, the simulated chemical injection in this research was fixed at $0.7 \mathrm{PV}$. In order to compare the efficiency of different injections, all processes take the same injection volume.

Polymer flood

To find a reliable polymer-flood injection system, several factors have been investigated to optimize the injection parameters, such as the molecular weight, injection rates, and solution concentration. Here, the optimization of molecular weight for the polymer flood is presented.

\section{Laboratory data}

All of the polymer properties are a function of the molecular weight in polymer flooding. At the same concentration, the key viscosity parameter will increase with the molecular weight. This research investigated three molecular weights and demonstrated how the behavior changed when the polymer solutions were injected into the formation. The molecular weights adopted were 4, 6, and 9 millions (HPAM). The viscosity curves are shown in Fig. 5. The adsorption curves are shown in Fig. 6.

\section{Viscosity and injection parameters}

Based on the mobility control function, the viscosity loss is the first concern for the application. In the model, several factors which related to viscosity loss have been considered. The loss from the pipeline flow (surface and wellbore) and the perforations was also estimated. A shearing model based on lab experiments has been used. The tested loss from brine was based on $\mathrm{NaCl}$; the viscosity change at 




Fig. 5 Viscosities of different polymers at different concentration

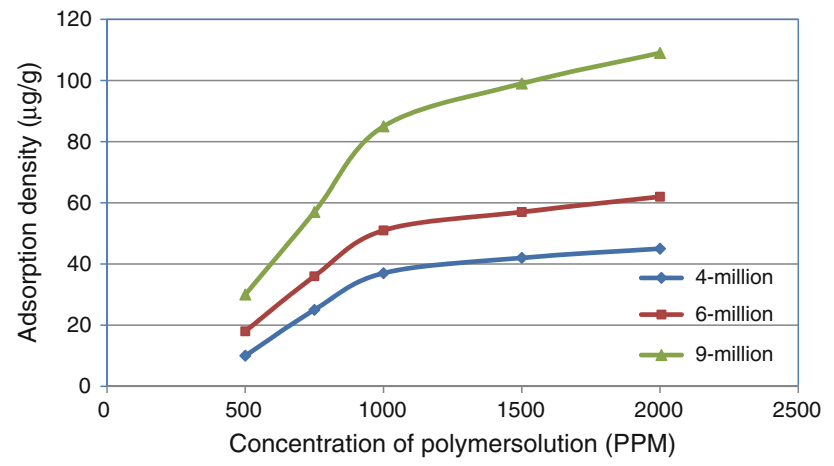

Fig. 6 Adsorptions of polymers at different concentration

different salinities was illustrated in the simulation. Taking the viscosity loss into account, the injection concentration is fixed at $1,200 \mathrm{ppm}$ to maintain the effective viscosity (adsorption). Injectivity reflects both the characteristics of the formation and the properties of the injected solution. For polymer floods, the injectivity is not only the parameter of interest, also demonstrated is the change of reservoir properties when the polymer solution is injected. The relevant formulas for initial individual rate used in this research are the following:

$\overline{H_{w j}}=\frac{1}{\alpha \cdot n} \sum_{i=1}^{n} \frac{H_{w j}+H_{o i}}{2}$,

$Q_{w j}=\frac{\overline{H_{w j}}}{\sum_{j=1}^{m} \overline{H_{w j}}} \cdot V \cdot P V$.

\section{Results}

When the polymer solution was injected into the formation, the sweep efficiency was significantly increased, as seen in Fig. 7 (6-million molecular weight). The channels formed by the water flood were improved, and the polymer caused the flood to move into the un-swept zones.

According to the predictions for different polymers, at 0.7 PV injection volume, the 6-million MW had the best

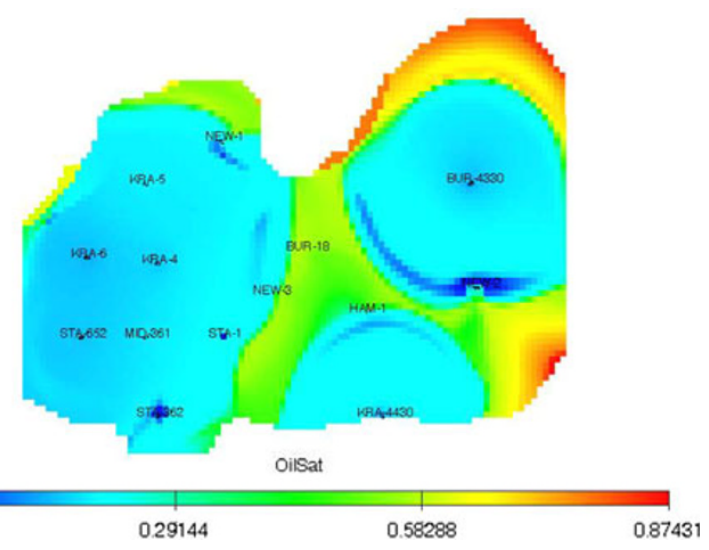

Fig. 7 Oil saturation after polymer flood (6 million)

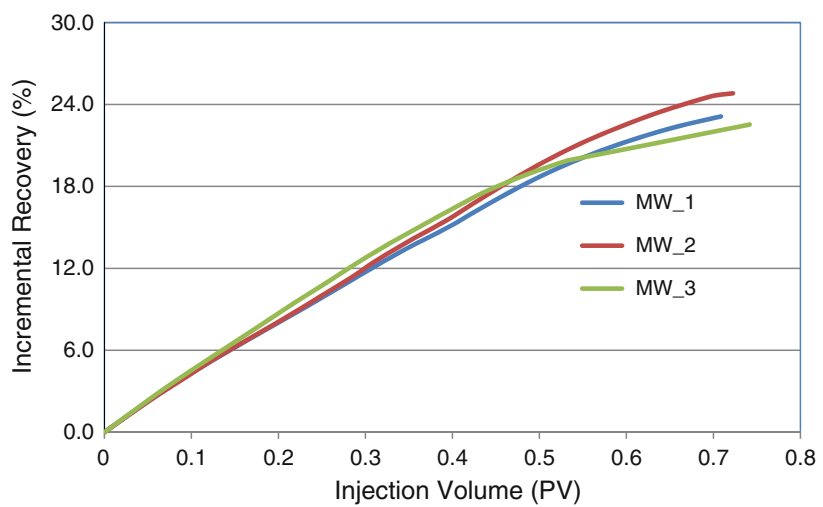

Fig. 8 Incremental recoveries from polymer at different injection volumes

incremental recovery factor of $24.74 \%$; the recovery factor of the 9-million MW was $22.01 \%$; the factor of the 4-million MW was $23.59 \%$, as seen in Fig. 8. The difference happened after $0.5 \mathrm{PV}$ injection, mainly because the relatively high molecular weight polymer had a lower recovery in flank zones. With increasing injection time, the 6-million MW polymer had an improved recovery efficiency, and the efficiency difference between the 6 million and the 9 million was enlarged. The cause of this phenomenon was that the injectivity of the 9-million polymer solution decreased due to the unsuitability between the formation and the polymer solution. By increasing the molecular weight to 9 million, there was a sharp downtrend in injectivity due to the effect of adsorption, and the decrease in permeability, especially near KRA-4430 and BUR-4330, was significant at the late injection phase. As a result, the recovery rate significantly decreased, as seen in Fig. 9.

\section{Application concerns}

Compared with successful floods, the polymer flood in the South Slattery field will have a longer development period, 


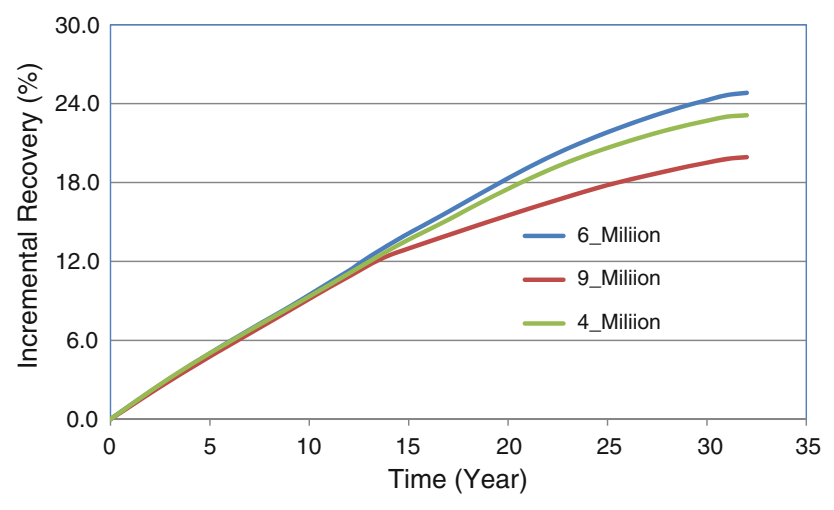

Fig. 9 Incremental oil recovery from polymer at different times

Table 2 Field water sample analysis

\begin{tabular}{lll}
\hline Components & Produced water & Injection water \\
\hline Calcium (mg/L) & 911 & 2.53 \\
Iron (mg/L) & 1.24 & $<0.01$ \\
Magnesium (mg/L) & 156 & 0.11 \\
Sodium (mg/L) & 21,400 & 332 \\
Potassium (mg/L) & 342 & 0.28 \\
Barium (mg/L) & $<0.01$ & $<0.01$ \\
Bicarbonate (as $\left.\mathrm{CaCO}_{3}\right)(\mathrm{mg} / \mathrm{L})$ & 499 & 381 \\
Carbonate (as $\left.\mathrm{CaCO}_{3}\right)(\mathrm{mg} / \mathrm{L})$ & 0 & 30 \\
pH, std. Units & 7.31 & 8.79 \\
Chloride (mg/L) & 29,101 & 35 \\
Sulfate (mg/L) & 4,507 & 310 \\
\hline
\end{tabular}

mainly because the injectivity of the whole field is favorable for a short-term injection. The average model permeability is only $23.3 \mathrm{mD}$. Developmentally, the well density is another unfavorable factor. The field injection rate is much lower than the capacity of the pore volume. Furthermore, the well spacing may fail to form effective driving pressure during a polymer application.

One more concern is the effects of high salinity in the reservoir fluid. The salinity of the Minnelusa formation water is relatively high. The initial salinity was close to seawater. The sodium salt accounts for around $92.5 \%$; the calcium salt accounts for 5.5\%; the magnesium salt accounts for the rest. The compositional analysis of the produced water can be seen in Table 2. Two main effects of the high salinity should be considered. One effect is the viscosity loss of polymer solution. In a high-salinity environment, the tendency of scrolling makes the motions of molecular chains weak, which gives rise to a serious viscosity loss. The other effect is polymer adsorption. The high salinity will speed up and increase the adsorption. The effect of divalent ions especially should not be ignored.

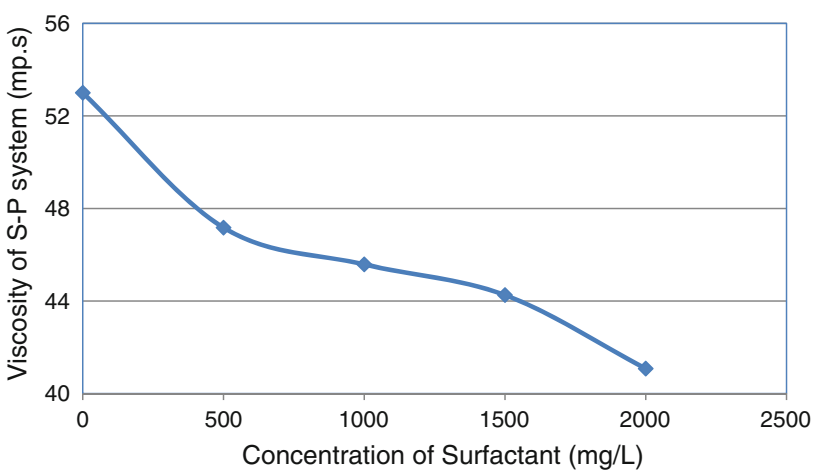

Fig. 10 Solution viscosity at different surfactant concentrations (1,200 $\mathrm{mg} / \mathrm{L}$ polymer solution system)

Surfactant-polymer flood

Compared with a polymer flood, the use of surfactant makes SP flooding more complicated. The slug design plays an important role in a flood. To develop a successful flood, adequate design of the injection process is required. Based on the literature and the experience of successful floods, two injection processes were simulated. The difference between these two processes is the use of prepolymer. In the first process, a pre-polymer slug was used. The initial thinking was that a small slug of pre-polymer solution can partially solve the channeling which was formed by the water flood.

\section{Laboratory data}

Surfactant Parameters of an anionic surfactant were used. Viscosity versus concentration is shown in Fig. 10. For the measurement of adsorption, Berea sandstone was used (the brine used to prepare the surfactant solution was $3.2 \% \mathrm{wt}$ $\mathrm{NaCl}$ ). The plot of the adsorption densities at different solution concentrations is shown in Fig. 11. Figure 12 shows the interfacial tension (IFT) change at different surfactant concentrations (measuring environment: 1,200 ppm polymer solution system, measured with crude oil from another Minnelusa field with similar oil properties). The 6-million MW polymer was used (the optimum polymer in the polymer flooding section, properties seen above).

\section{Injection case}

Process 1:

1. Pre-flush 6 months (0.3 PV) water flood, which was the volume of brine to lower resident salinity.

2. Pre-polymer $0.15 \mathrm{PV}, 1,000 \mathrm{ppm}$ polymer solution, which was to minimize by-passing and channeling, and 


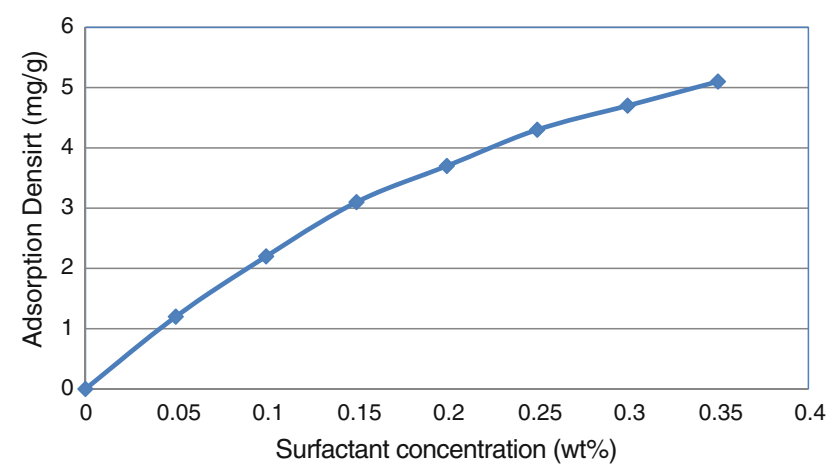

Fig. 11 adsorption densities of surfactant at different concentrations



Fig. 12 Interfacial tension at different surfactant concentrations

to make sure that the surfactant-polymer slug, can reach a considerable volumetric coverage.

3. S-P slug $0.45 \mathrm{PV}$, the main slug of surfactant and polymer, the concentration of surfactant was $1,200 \mathrm{ppm}$, concentration of polymer was $1,200 \mathrm{ppm}$.

4. Mobility buffer $0.10 \mathrm{PV}, 600 \mathrm{ppm}$ polymer solution, which was a dilute solution. The purpose was to drive the S-P slug and banked-up fluids toward the production wells.

5. Chase water This fluid was injected to reduce the cost of continuous injection of polymer.

Process 2:

Based on the above procedure, process 2 removed the pre-polymer slug, and the slug size of S-P was increased to $0.6 \mathrm{PV}$.

\section{Flood efficiency and recovery}

The predictions of the two processes that showed the displacement efficiency in the central reservoir were significantly improved due to the desaturation function of surfactant; the remaining oil zone was minimized since the sweep efficiency has been improved significantly. However, the southeastern corner still had a remaining oil rich

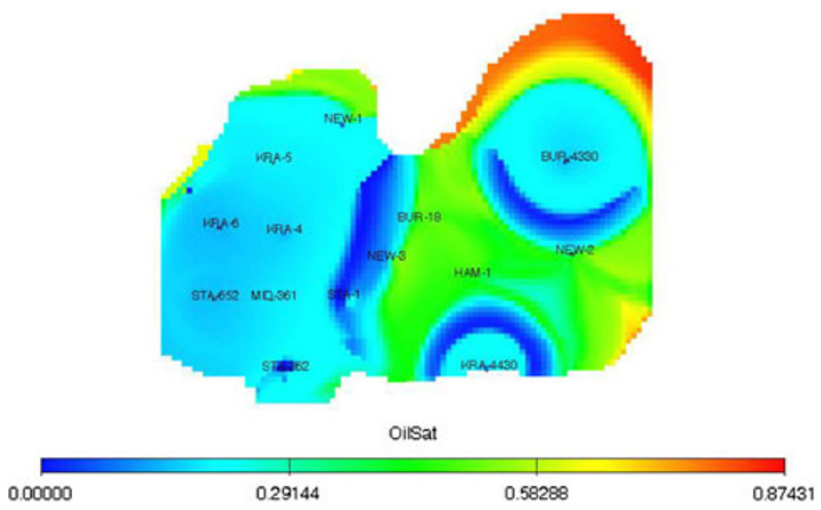

Fig. 13 Remaining oil distribution after the buffer slug

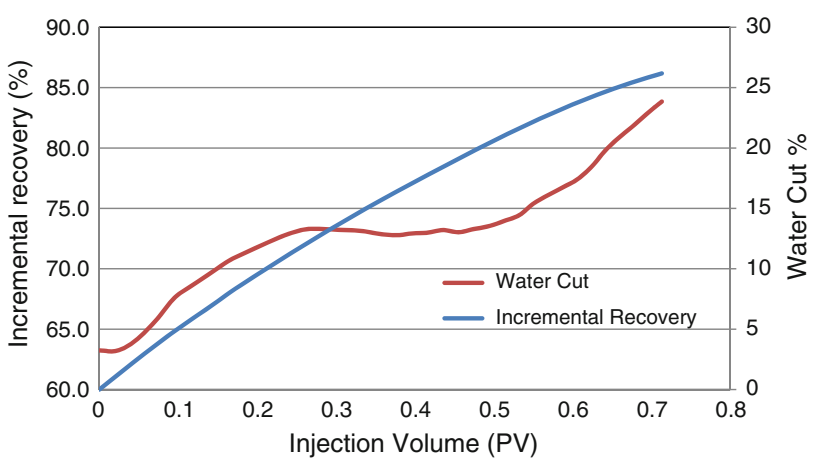

Fig. 14 Water cut and incremental recovery against injection volume in S-P (process 1)

zone, principally due to the low injectivity of well KRA4430. The injection volume from KRA-4430 was not enough to mobilize the oil bank further. Figure 13 shows the oil saturation distribution after process 1 .

The oil saturation distribution showed that process 1 had the better sweep efficiency. The pre-polymer slug played its role. But the displacement efficiency of process 1 , especially in the relatively high-perm zone, was a little lower than that of process 2 . Compared with the polymer flood at $0.70 \mathrm{PV}$ of injection, process 1 had another $2.49 \%$ incremental recovery in addition to what the polymer flood did. The recovery factor of process 1 showed $0.43 \%$ higher than that of process 2 .

The difference between the results of processes 1 and 2 can be accredited to the pre-polymer slug. In the process 1 , the $0.1 \mathrm{PV}$ of low concentration polymer solution had a profile control function which slightly improved flow environment of the following injections. The injected surfactant had a wider sweep area compared with the injection in process 2 .

The incremental recovery and water cut of process 1 are shown in Fig. 14. According to the water cut curve, from $0.26 \mathrm{PV}$ injection volume, the water cut began decreasing, not as significantly as the polymer flood did; however, it 
Table 3 Recovery Summary of different EOR Methods

\begin{tabular}{|c|c|c|c|c|c|}
\hline \multirow{2}{*}{$\begin{array}{l}\text { Method } \\
\text { Simulation case }\end{array}$} & \multicolumn{3}{|l|}{ Polymer } & \multicolumn{2}{|c|}{ Surfactant-polymer } \\
\hline & 4 million & 6 million & 9 million & Process 1 & Process 2 \\
\hline Ultimate recovery $(\%)$ & 58.21 & 60.78 & 59.13 & 63.27 & 62.84 \\
\hline Incremental value of OOIP $(\%)$ & 6.23 & 8.80 & 7.15 & 11.29 & 10.86 \\
\hline
\end{tabular}

kept the water cut from increasing for a longer time; thus, the peak oil period was extended.

\section{Application concerns}

Besides the above concerns about the polymer flood, the SP injection has a few more issues to be considered: the estimation of the critical micelle concentration at the reservoir conditions which depends on the salinity and $\mathrm{pH}$. The salinity distribution after 14 years of water injection is a critical factor to the evaluation of chemical injections. The employed simulator is not able to simulate ion exchange and the existence of emulsions. But the desaturation function is perfect to reflect the residual oil saturation change based on IFT alteration. A further research would be needed to investigate the estimation of mechanisms of the surfactant-related injection which could be used to offer verified parameters for a detailed simulation research.

\section{Discussion}

The recovery factory for each case can be seen in Table 3 . The incremental value displays the incremental recovery based on the adjusted water flood. The optimum polymer flood has a recovery contribution of $8.80 \%$. The optimum surfactant-polymer process has another $2.49 \%$ incremental recovery based on polymer flood. Economics analysis is necessary for the comparison and estimation of these EOR methods in the further research.

Due to the high salinity of Minnelusa water at the Slattery, the effects of salinity which relates to the viscosity loss of polymer floods and the interfacial tension change during a surfactant injection were considered cautiously. Making a further estimation of salts distribution in the formation is necessary. Specifically, the viscosity losses of polymer floods also include the effects of shear. The viscosity loss from reservoir flow was considered accurately in the model. The losses from other factors should also be modeled accurately for a further polymer simulation. Combining the lab analysis, the damages due to chemical floods, like chemical adsorptions, wettability alteration, and permeability reduction have to be considered to estimate the injection efficiency.

\section{Conclusion}

1. Based on the water-flooding history match, the recovery was $36.13 \%$ of the water flood. To get a better effect in EOR simulation, a network adjustment was made to improve the injection and production pattern. The ultimate recovery of the new well pattern is $3.85 \%$ higher than that of the old pattern.

2. The polymer flood significantly improved the sweep efficiency. For the three kinds of polymers of different molecular weights, the 6-million MW polymer was more suitable for the South Slattery Field. The estimated incremental recovery was $8.80 \%$ compared with that of water flood.

3. The optimum S-P process increased the recovery by $2.49 \%$ compared to the polymer flood at $0.70 \mathrm{PV}$ of injection. The use of pre-polymer slug improved development efficiency after a sort. The analysis of the predictions showed the remaining oil saturation that mainly depended on the sweep efficiency of SP slug.

Acknowledgments Support for this work by the Enhanced Oil Recovery Institute of the University of Wyoming, under the direction of David Mohrbacher, is gratefully acknowledged.

Open Access This article is distributed under the terms of the Creative Commons Attribution Noncommercial License which permits any noncommercial use, distribution, and reproduction in any medium, provided the original author(s) and source are credited.

\section{References}

Carcoana A (1991) Applied enhanced oil recovery. New Jersey, Prentice Hall

Chang HL, Zhang ZQ, Wang QM, Xu ZS, Guo ZD, Sun HQ, Cao XL, Qi Q (2006) Advances in polymer flood and alkaline/surfactant/ polymer processes as developed and applied in the People's Republic of China. J Petrol Technol 58:84-89

David B, Gary A (2003) Selection and screening of polymers for enhanced-oil recovery. Presented at the SPE/DOE improved oil recovery symposium, Tulsa, OK, 19-23 Apr 2006, Paper SPE 113845

Gabitto JF (2006) Combined microbial surfactant-and-polymer system for improved oil mobility and conformance control. Presented at the 2006 SPE annual technical conference and exhibition, San Antonio, TX, Paper SPE 102328 
Gharbi RBC (2001) A knowledge-based system for optimal economic design of improved recovery processes. Presented at the SPE Asia Pacific oil and gas conference and exhibition, Jakarta, Paper SPE 68765

Kaminsky RD, Szafranski RC (2007) Guidelines for polymer flood evaluation and development. Presented at the international petroleum technology conference, Dubai, Paper IPTC 11200

Osterrloh WT, Jante MJ (1992) Surfactant-polymer flood with anionic PO EO surfactant microemulsions containing polyethylene glycol additives. Presented at the SPE/DOE improved oil recovery 8th symposium, Tulsa, OK, Paper SPE 24151

$\mathrm{Pu} \mathrm{H}$, Yin D (2008) Feasibility study and pilot test of polymer flood in third class reservoir of Daqing oilfield. Presented at the 2008 SPE North Africa technical conference and exhibition, Marrakech, Paper SPE 111720
Sheppy RJ (1986) Slattery field, Powder River Basin, Wyoming: a multidisciplinary interpretation of a complex Minnelusa (Permian) field. In: Wyoming Geological Association symposium on Rocky Mountain oil and gas fields. Wyoming Geological Association, Casper, pp 245-256

Sorbie KS, Phil D (1991) Polymer-improved oil recovery. CRC Press, Florida

Towler BF (1991) Simulation of South Slattery Field, a Minnelusa 'A' Reservoir. Presented at the Rocky Mountain regional meeting and low-permeability symposium, Denver, CO, Paper SPE 21816

Wang YP, Li H (2006) Commercial success of polymer flood in Daqing oilfield-lessons learned. Presented at 2006 SPE Asia Pacific oil and gas conference and exhibition, Adelaide, Paper SPE 100855 